Primer semestre de 2019 - pp. 107-122

Segunda época

N.o 10

\section{El caso del Festival del Burro en San Antero (Córdoba): parodia y redención social}

$\begin{array}{ll}\text { The Case of the } & \text { O caso do Festival } \\ \text { Donkey Festival in } & \text { do Burro, em San } \\ \text { San Antero (Córdoba): } & \text { Antero (Córdoba): } \\ \text { Parody and Social } & \text { paródia e redenção } \\ \text { Redemption } & \text { social }\end{array}$

The Case of the

Dan Antero (Córdo

Parody and Social

Redemption 


\section{Resumen}

El Festival Nacional del Burro, que en 2018 celebró su XxxI versión en el Municipio de San Antero (Córdoba), se desarrolla en Semana Santa y consiste en un ritual en el que se ridiculiza la realidad sociopolítica reciente, usando como instrumentos los burros disfrazados. Sin embargo, esta compleja expresión regional se caracteriza por diversos elementos rituales, y aquí interesa no sólo analizar el "concurso de burros disfrazados", sino, preferentemente, el acto llevado los Sábados de Gloria, conocido como "el paseo de Judas Iscariote". Para satisfacer este objetivo, se acudió a algunos principios del análisis discursivo, bajo premisas obtenidas de van Dijk $(2000,2008)$, Fairclough (1998) y Renkema (1999). Los resultados de tal esfuerzo permiten comprender algunas causas que explican la función comunicativa del Festival, al tiempo que devela una transculturación de otros eventos similares, y cuya acción se centra en un símbolo que permite exorcizar el mal social y corregir imaginariamente la realidad compartida. Para satisfacer nuestra meta, el artículo se organiza en cuatro apartados: el marco teórico, que da cuenta de apuesta conceptual de lo festivo; el marco metodológico, que despliega los momentos analíticos de los eventos festivos; la sección de resultados del examen propiamente efectuado y, finalmente, las conclusiones.

\section{Palabras clave}

festival; símbolo; imitación; congregación; liberación

Abstract

The National Donkey Festival, which celebrated its 31 st edition in the Municipality of San Antero (Córdoba) in 2018, takes place during Easter and is a ritual in which the most recent sociopolitical reality is ridiculed through donkeys wearing costumes. However, this complex regional form of expression is characterized by different ritual elements, and the purpose here is not only to analyze the "dressed donkey contest," but also, preferably, the act known as "The Parade of Judas Scariot," which takes place on Saturday of Glory. To that end, we used as basis some principles of discursive analysis, under the premises obtained from van Dijk $(2000,2008)$, Fairclough (1998), and Renkema (1999). The results of this effort allow us to understand some of the causes that explain the communicative purpose of the Festival; they also reveal a transculturation of other similar events and the festival's focus on a symbol that allows the exorcism of the social evil and the imaginative correction of the shared reality. To fulfill our goal, the paper is divided in four sections: the theoretical framework, which describes the theoretical concept of festivity; the methodological framework, which unfolds the analytical moments of festive events; the results of the actual study, and, finally, the conclusions.

\section{Keywords}

festival; symbol; imitation; congregation; liberation

\section{Resumo}

O Festival Nacional do Burro, que em 2018 teve sua xxxı edição no município de San Antero (Córdoba), se desenvolve em semana santa e consiste em um ritual no qual se ridiculariza a realidade sociopolítica recente, utilizando como instrumentos os burros fantasiados. Contudo, essa complexa expressão regional está caracterizada por diversos elementos rituais e aqui interessa não só analisar o "concurso de burros fantasiados", senão, preferentemente, o ato realizado os Sábados de Gloria, conhecido como "0 passeio de Judas Iscariote". Para satisfazer este objetivo, acudimos a alguns princípios da análise discursiva, sob as premissas obtidas de van Dijk (2000. 2008), Fairclough (1998) e Renkema (1999). Os resultados desse esforço permitem compreender algumas causas que explicam a função comunicativa do Festival, ao tempo que revela uma transculturação de outros eventos similares, e cuja ação está centrada em um símbolo que permite exorcizar o mal social e corrigir imaginariamente a realidade compartilhada. Para conseguir nosso propósito, o artigo está organizado em quatro seções: o marco teórico, que dá conta da aposta conceitual do festivo; o marco metodológico, que despliega os momentos analíticos dos eventos festivos; a seção de resultados do exame propriamente efetuado e, finalmente, as conclusões.

\section{Palavras-chave}

festival; símbolo; imitação; congregação; liberação 


\section{Preámbulo}

Aunque los estudios teóricos sobre lo festivo en América Latina son relativamente nuevos, pues apenas cuentan con medio siglo de reflexiones sistemáticas (Lara, 2014), parece innegable que los enfoques al respecto coinciden en entender que sus realizaciones (v. gr. festivales, carnavales, carnestolendas, etc.) son escenarios donde se representan los grandes e iterativos temas de la sociedad, y cuyo funcionamiento interno está fuertemente marcado por artificios simbólicos, pues en ellas aparecen encarnados de manera teatral y plástica un conjunto de elementos figurados, ideológicos, normativos y desiderativos de quienes las viven.

Ya en el caso de la cultura colombiana, hay una abundante manifestación de lo festivo, y los estudios sobre festividades locales, aunque desde disímiles perspectivas, han dado cuenta de su funcionalidad; verbi gracia, los casos representativos de la antropóloga De Friedemann (1985, 1995), del historiador González Pérez $(1998,2016)$ o de la investigadora Triana $(2000,2006)$. No obstante, no despunta aún un estudio escrupuloso sobre ciertos festivales que acontecen en la costa caribeña de nuestro país, cubiertos predominantemente con noticias en prensa local y algunos pincelazos en los inventarios de los investigadores consagrados a este tema. Esto es lo que sucede con el Festival del Burro, celebrado anualmente en el municipio de San Antero (Córdoba), y que, a pesar de sus ya más de tres décadas de pervivencia en su versión moderna (y casi un siglo de existencia), es aún ignoto en muchas capas sociales y académicas. De esta suerte, es nuestro interés centrarnos en este evento festivo y adelantar un análisis, tanto estructural como relacional, aprovechando herramientas que proveen algunos modelos inscriptos en el campo interdisciplinar del análisis discursivo; pues apostamos, como se especifica más abajo, que la naturaleza de lo festivo posee cuatro aristas esenciales, dentro de las cuales rescatamos el comunicativo-discursivo como el eje que ajusta y domina los otros tres: el folclórico, el antropológico y el sociológico.
Lo atractivo de este esfuerzo es que, tras un sustento teórico y una apuesta metódica, edificamos una hipótesis sobre el sentido y tradición de este Festival basados, primero, en el entendimiento contextual de algunos de sus símbolos y rituales discursivos ( $v$. gr: burro, Judas, Testamento) y, segundo, en sus conexiones inter-discursivas con otros eventos festivos iberoamericanos, lo cual aprovechamos para pensarnos en esta época que vivimos y que tanta esperanza acuña para reconstruir una nación fragmentada y aún poco comprendida. Pues bien, para desarrollar esta apuesta, adelantaremos una reflexión teórica sobre lo festivo, lo cual nos permite acercarnos al Festival objeto de nuestra atención con una línea de análisis determinado; $y$, posteriormente, describiremos de forma sucinta la postura metódica que permitió leer en clave discursiva tal objeto sociocultural, mostrando lo más relevante de su análisis y las soluciones transitorias a las que hemos llegado en su intento por comprender el fenómeno sociorritual.

\section{Fundamentos teóricos}

Algunas plataformas teóricas permiten pensar, en primera instancia, en la inclusión de lo festivo dentro del enfoque folclórico, si entendemos que el folclor es el rostro más visible de los fenómenos culturales populares de una colectividad. Es que, a través de las fiestas sus participantes, sin ninguna restricción social ni étnica, exteriorizan prácticas sociales híbridas, y también vivencias de su devenir, las cuales se pueden describir para inferir de estas acciones los "rasgos de la cultura popular tradicional de un determinado sitio o región" (Pereira, 2009, p. 138).

Así, pues, y dejando al lado aquellas nociones de lo festivo que lo reducen a concepciones simplistas y ligeras afirmando que son encuentros usados para expresar directamente alegría (v.gr. Ocampo, 1985), una delimitación folclórica de la noción de lo festivo permite afirmar que son acciones donde los sujetos participantes logran, desde sus actos est-éticos, actualizar sus cosmovisiones, preservar claves identitarias a través de enclaves identificatorias y reforzar sus lazos sociales. Al respecto, Pereira (2009) afirma: 
Hoy debemos considerar la fiesta como un espacio cargado de hechos y personajes simbólicos, mediante los cuales cada pueblo en particular reactualiza la visión que tiene de sí mismo y del mundo que le rodea. En ella reordena y orienta cíclicamente las relaciones al interior del grupo, redistribuye instancias de poder y prestigio y, sobre todo, se reproduce a sí mismo comunicándoles a sus miembros los símbolos portadores de su identidad y voluntad de ser distintos. (pp. 24-25).

Esta perspectiva de lo festivo como acción cíclica revitalizadora, como segunda vida de un pueblo, también es compartida por los sociólogos Ariño (1996) y Miranda (2009); algo que, en el caso colombiano vino a ser complementado en las décadas de 1970-1980 por la antropóloga bogotana Nina de Friedemann (1985), precursora indiscutible en el análisis del Carnaval de Barranquilla, tal como lo corroboran Martha Lizcano y Danny González (2009), investigadores de la Universidad del Norte. Así, pues, con los aportes de la antropología, muy posteriores a los de la mirada folclórica, y también de los debates sobre $l o$ popular agenciados en Colombia de forma brillante por el filósofo español Jesús Martín-Barbero (1987, 1992) $)^{1}$, las fiestas comenzaron a ser comprendidas al tiempo como un hipónimo de folclor y como un ritual, ya que en su estructura se reavivan hechos sociales que, siendo periódicamente repetidos o actualizados simbólicamente, expresan, catalizan y depuran problemas del tejido social mismo (Escalona, 2012); función que, en su dimensión fija o estructural nombra, apoya, inmoviliza o recupera sucesos molestos en momentos muy específicos de manera convencional con el fin de corregir lo torcido en el orbe social, mientras que en su dimensión flexible o antiestructural, añade creativamente nuevos contenidos y estereotipos (Turner, 1988).

Esto es, la fiesta es un tipo de ritual porque posibilita una pasajera panacea a través de rituales comunicativos acreditados bajo la lógica lúdica que admite, por un lado, evaluar relaciones de poder; $y$,

1 Para Martín-Barbero, lo popular fue por mucho tiempo la cultura subalterna y desvalorizada frente a la cultura hegemónica; no obstante, al ser revalorizada por enclaves políticas, se ha venido instalando como parte de la nación, incorporada a la modernidad y al mundo. por otro, generar discordias temporo-espaciales que permiten sospechar otros porvenires; volviéndose así en un espacio de innovación colectiva de otros mundos y otras formas de probar el orden cultural establecido. De esta suerte, la fiesta envuelve complejos mecanismos de cohesión o cemento social y de conflicto o tensión frente a los poderes hipostasiados; en términos de González Pérez (1998), son dispositivos "de cohesión, dado que en la fiesta se crean espacios de unanimidad alrededor de imaginarios sociales que tejen formas elementales de sociabilidad en una comunidad; de conflictos, dado que la fiesta permite poner en escena los imaginarios del poder" (p. 8).

En este orden de ideas, afirmamos que, en principio, las fiestas son procesos dobles: rituales y folclóricos, llevando en su esencia la intención de una revolución innovadora, de una protesta que pone entre paréntesis la rutina social de un colectivo, y que no necesariamente se asimilan a los calendarios festivos de una nación, sabido por todos, establecidos por discursos de poder político y hasta económico. Sobre esto último, baste aludir al calendario colombiano, que presenta 18 celebraciones con fechas reglamentadas entre fiestas patrias, civiles y católicas (le sigue Argentina, con 16), de las cuales la mayoría son trasladadas a los días lunes, gracias a la Ley Emiliani de 1983; pero, también, cuenta con 107 días especiales, que son fiestas espontáneas y que no obligan a interrumpir la cotidianidad social (v. gr. 23 de abril, Día del Idioma; 1 de junio, Día del Campesino; 13 de agosto, Día del Humorista; 25 de octubre, Día del Instrumentador Quirúrgico, etc.), a lo que se debe sumar el calendario lunar indígena (basado en deidades y mitos locales), los fenómenos festivos con nuevas formas de escenificación (como las fiestas de dignificación de la memoria a través de conmemoraciones a las minorías étnicas) y las neoformas festivas ejecutadas en las marchas simbólicas de protesta, como aquellas teatralizadas contra el fanatismo, la violencia, los toreros, las minas antipersona; o aquellas a favor de los niños, de los desplazados, de un candidato presidencial, etc. (González, 2016). 
Incluso, por los estudios pretéritos de González Pérez (1998), sabemos que Colombia es el país más festivo de América Latina, puesto que en un año hay más de 3800 fiestas, entre las que se cuentan más de 140 carnavales. De hecho, algunos festivales suceden de forma invisible, como el Carnaval de Britalia, en la localidad de Kennedy, Bogotá D.C., y otros de manera arbitraria, como el Festival de Verano en Bogotá, celebrado desde 1997, el cual ocurre casi siempre en época de fuertes lluvias; pero, incluso:

[...] en Colombia hay muchas fiestas simultáneas; por ejemplo, el Carnaval de Negros y Blancos se celebra en más de 70 municipios de Cauca y Nariño. En promedio cada festividad en Colombia dura tres días. Hay fiestas de ocho días como la de San Pacho, en Chocó, de tres o cuatro días como el Carnaval de Barranquilla, o de un día como el Carnaval del Cuy, en el departamento de Nariño. Por eso, si usted quiere vivir la manifestación festiva de Colombia, tendría que dedicar 10 años de su existencia todos los días a vivir las fiestas. (El Tiempo, 10 de febrero de 2005).

A esta larga lista, hay que añadir ferias, carnestolendas privadas, jolgorios comunitarios, fiestas patronales, festivales municipales y fiestas con reinados de belleza, que serían la antítesis de las carnestolendas ${ }^{2}$, pues en los reinados de belleza lo que importa es la exposición de las carnes de las reinas de belleza, así sean reconstruidas artificialmente. A comienzos del siglo xxI, el Reinado de Cartagena, fue elegido por los colombianos como la fiesta nacional más representativa, según una encuesta del Ministerio de Cultura. Al respecto, en 2008 el semiólogo bogotano Armando Silva afirmaba:

En estadísticas que hice sobre los reinados de belleza en Colombia encontré que cada 13 días se elige una soberana nacional y que, si agregásemos reinados de bazares, barrios, pueblos, se puede decir que en los 365 días del año se producen tantas reinas como lo hacen otras industrias

2 Carnestolenda es un italianismo que significa "despedirse de la carne" o "carnes que han de quitarse, para dar lugar a la abstinencia de la época de cuaresma" (carnevale), y que son un tipo de fiestas o carnavales que introdujeron culturalmente los españoles a América en el siglo xvı, y que se caracteriza por ser celebraciones que mezclan la fiesta misma con toros, cabalgatas y juegos de azar. exitosas, sea el café o la música tropical, y que entonces nacer mujer en Colombia trae el riesgo muy probable de un día convertirse en reina de belleza. (Silva, 2008).

Lejos de parecer una exageración, Silva parece haberse quedado corto con el estudio estadístico, pues en 2015 el diario británico $B B C$ confirmaba que en Colombia hay más de diez fiestas con reinados por día:

Colombia es uno de los países con más fiestas con reinados al año: 3794. Y concluye que, así como Colombia esperó 56 años y 184 días para recibir la corona del mundo [Miss Universo 2014-2015, Paulina Vega Dieppa], también tardó 20 años en indignarse por un concurso en un pequeño pueblo. Según la publicación, en el país del Sagrado Corazón hay reinado de la panela, de la gallina campesina, del burro, de la guayaba, del frío y hasta la antítesis del reinado del más feo del mundo. (Revista Semana, 30 de enero de 2015).

Visto así el panorama festivo nacional, la superabundancia de conmemoraciones, con o sin reinado de belleza, permite que el espacio político nacional o la polis se transforme en un territorio o urbs (Delgado, 1999), cada vez que la fiesta no solo afecta y contamina los tiempos sociales, sino también los espacios, lo que permite aseverar sin temor que esta es una de las estrategias privilegiadas que los moradores en nuestra cultura aprovechan para habitar y apropiarse de la polis, reduciéndola a cartografías lúdicas; esto es, a topos subjetivizados, performativizados y empleados para el encuentro identitario y escenificación de las sensibilidades ciudadanas. Así que la geo-política im-puesta termina convertida en un conjunto de mapas mentales en la cognición de los ciudadanos, certificando no solo aquella premisa de la semiótica urbana que afirma que los mapas mentales anteceden los mapas reales (Silva, 2009), sino también aquella máxima de Bajtín (1989), para quien el carnaval presenta diferencias con las ceremonias oficiales que impone el calendario estatal, ya que en aquellas todo el cuerpo sensorial se atraviesa de caos, condición que admite la recreación del cronos público e instala la ordenanza primigenia en un topos desnaturalizado y gobernado por lógicas de cohesión y compadrazgo. 
De esta suerte, ante nuestra concepción dual de lo festivo, basada en los enfoques folclórico y antropológico, se suman dos aristas al concepto, y que llamaremos posturas sociológica y comunicativa, y que coinciden en lo cardinal, que se con-funden. A partir de la primera, se puede deducir que es viable entender las fiestas como actos sociales proteicos y uniformes, puesto que lo festivo genera una imagen de común-unión; es decir, elementos imaginarios que unen a muchos miembros quienes, aunque no se conozcan -y nunca lleguen a hacerlo-, los une una pasión imaginada de fusión; o mejor decir, de corp-oración, tal como lo explicara hace más de tres décadas el historiador Benedict Anderson (1993), y que explicita que en toda comunidad o congregación un miembro concibe a los demás como suyos gracias a la imagen de comunidad que los envuelve a todos. Y, a partir de la segunda nueva postura, y la cuarta de la lista, la fiesta es una máquina comunicativa, puesto que es, en esencia, un discurso de discursos; esto es, un agregado de textos culturales circulando en contextos diversos y donde circulan signos, códigos y referentes bajo ciertas reglas de combinación, y cuyo encuadre es el rostro ritual (Roiz, 1982). De hecho, sostenemos que este eje, el comunicativo/ discursivo ${ }^{3}$, es el ombligo de la comprensión integral que proponemos sobre la naturaleza de lo festivo puesto que, como advertimos, cada uno de los otros rostros descritos se simbolizan en variopintos códigos semiolingüísticos y porque es la comunicación la que, finalmente, genera los hechos sociales y los recrea (Echeverría, 2008). De hecho, en 1950, el escritor mexicano Octavio Paz afirmaba que, en la fiesta, el espacio y el tiempo ordinarios se vuelven otros y los asistentes comulgan consigo mismos. Esto es, la fiesta es un espacio de comunicación, de comunión; y también de su posible anulación, porque "entre nosotros la fiesta es una explosión, un estallido. Muerte y vida, júbilo y lamento, canto y aullido se alían en nuestros festejos, no para reco-

3 Para Cortés y Camacho (2003), los discursos son “objetos lingüísticos concretos, producidos en situaciones determinadas en las que han incidido todo tipo de aspectos extralingüísticos: sociales, ideológicos, políticos, personales, etc." (p. 28). nocerse sino para entredevorarse [...]. La noche de fiesta es también noche de duelo" (Paz, 2004, p. 57).

Así las cosas, si unimos estos cuatro rostros teoréticos tratados sucintamente, el folclórico, el antropológico, el sociológico y el comunicativo, este último como ombligo anudante, consumamos una definición más versátil de lo festivo, de lo que resulta la idea de eventos que, siendo parte del tesoro folclórico de una nación o región, actúan ritualmente (lo que implica, de paso, la actualización de un mito). Pero, también son eventos dinámicos y de denuncia social, que crea vínculos imaginarios entre sus asistentes, lo que mantiene cohesionados sus miembros; por lo que, de suyo, permite que ellos re-velen o reflejen los funcionamientos sociales de ese compuesto de sujetos; esto es, que informen aspectos culturales cardinales.

Pues bien, completado este primer esfuerzo, ahora queda acercarnos a algunas de las fiestas populares locales en Colombia, centradas en la región que nos interesa, la zona costera Caribe, puesto que allí se instala un festival al que deseamos prestar atención analítica: el Festival del Burro. De nuevo, retomando los estudios de González Pérez (2016), en el calendario regional del folclor caribeño abundan las fiestas en poblados de raíces afrocolombianas, cuyo centro de atención es la combinación de danzas, música y el acto de la disimulación, materializada en el disfraz o la careta. Así, son ejemplos fascinantes que revelan esa combinación entre baile, música aborigen y disfraz, el Festival vallenato, en Valledupar; el Festival Nacional de Compositores de Vallenatos, en La Guajira; el Carnaval de Barranquilla, Patrimonio Inmaterial de la Humanidad en 2003; el Festival del Mar, en Santa Marta; el Festival de Tambores y Expresiones Culturales de San Basilio de Palenque, en Bolívar; el Festival del Bullerengue en Montería, Córdoba, y también el Festival del Porro, en San Pelayo, Córdoba.

Y, dentro de estos festivales en Córdoba, aparece también el Festival Nacional del Burro, que se realiza en el municipio de San Antero, pueblo fundado hace 371 años y que queda ubicado a unos 70 kilómetros de su capital, Montería. El festival tiene su origen en 1925 y, desde entonces, se ha realizado cada Semana 
Santa en torno a un muñeco que representa al apóstol Judas, quien es paseado en un burro por las zonas públicas del municipio, convirtiéndose, así, en su símbolo más representativo. Es tradición, también desde su origen, que en el recorrido nombrado alguien vaya denunciado a los habitantes sucesos cualificados por presentar actantes con conductas impúdicas. Es decir, es un ejercicio que pretende, a través de la denuncia pública de actos como las rivalidades, la discordancia grupal, la infracción a la ley, el abuso de las autoridades, la unidad identitaria forzosa, las pugnas por el reconocimiento político, los actos de memoria histórica, etc., limpiar la inmoralidad y las malas costumbres, lo que le da una cualidad no solamente folclórica, sino claramente ritual y comunicativa.

No obstante, desde 1987, con el fin de conservar la idiosincrasia del pueblo sananterano, centrado en su dependencia asnar para cargar agua y leña y como medio rural de transporte, surge la idea de hacer del evento tradicional un festival turístico; a tal punto que ya se habla del "Festival del Burro y de la Semana de la San Antenaridad”. Y, para lograr ese doble fin, el municipio escogió el burro como insignia hegemónica del evento porque, por un lado, se asocia con el hombre laborioso y de aguante resignado, unido a la imprescindible compañía del animal en las labores agrícolas y ganaderas de Córdoba, y por otro, dada su evidente connotación religiosa, puesto que Jesús nació en un portal donde estaba un burro, símbolo de humildad, y también porque lo usó para entrar a Jerusalén, bajo la ovación y mirada de una multitud que le tendía ramas de árboles y mantos a su paso. De hecho, el nombre mismo del municipio remite al decimonoveno papa de la Iglesia Católica y es reverenciado como mártir cada 3 de enero.

\section{Apuesta metodológica}

De esta manera, asistimos a un evento que, dada su fisionomía comunicativa como eje anudador/ integrador en su entendimiento teorético, es posible analizar el Festival del Burro como un discurso multifacético apoyado en algunas claves propias del campo de investigación interdisciplinar asociado al análisis contextual de los productos de la comunicación cotidiana, conocido como análisis del discurso (AD) (Brown y Yule, 1983). Ahora, amparados en este campo, los discursos vistos como objetos de comunicación, tienen tres dimensiones que deben acatarse en su análisis (Van Dijk, 2000, 2008), a saber:

a. El lenguaje en uso (plano textual), que conforma el nivel observable o superficial;

b. La comunicación de creencias (plano representacional), que da materia al nivel del significado $\mathrm{y}$, finalmente,

c. La interacción en una situación comunicativa determinada (plano interactivo o interpersonal), que da forma al nivel de lo que se hace o lo que se pretende hacer en la comunicación.

No obstante, el despliegue de estas dimensiones genera numerosos modelos dentro del campo, los cuales se guían en las tres dimensiones o planos de los discursos y, desde allí, promueven modelos de intervención analítica. A manera de ejemplo, contrastamos dos posturas para confirmar esta tesis; la del lingüista holandés Jan Renkema (1999), para quien los estudios discursivos son un campo investigativo que estudia la relación entre la forma y la función en la comunicación, y la de Norman Fairclough (1998), profesor de la Universidad de Lancaster (Reino Unido).

A partir de esta determinación común en todos los ponentes del AD, propone Renkema el siguiente método:

a. Secuencia oracional. Un discurso es un entramado sígnico que debe satisfacer estándares de cohesión y coherencia, además presenta intertextualidad, lo cual le da informatividad y aceptabilidad.

b. Secuencia proposicional. Los tópicos se distribuyen esquemáticamente en superestructuras, anudando, de forma global, macroestructuras. 
c. Acto-de-habla. La intención discursiva se cristaliza a través de requisitos comunicativos, como el principio de cooperación y las cortesías. Aún más, sus variaciones dependen de los tipos/modos discursivos usados y de los estilos elegidos, dependiendo de la situación comunicativa.

Todo esto, mientras que Norman Fairclough (1998) propone, asimismo, tres momentos:

a. Práctica textual. Los discursos se presentan en modalidades oral o escrita. En este nivel, la unidad de análisis son los textos, lo que implica prestar atención a lo sintáctico, lo léxico-semántico o lo pragmático. Su finalidad es descriptiva.

b. Práctica discursiva. $\mathrm{O}$ aspectos sociales y cognitivos de producción/interpretación de los textos. En este momento, se aprovecha el momento analítico previo y se coteja con las prácticas discursivas e institucionales en las que aparece inserto ese texto. Este cotejo se logra al relievar el texto desde una perspectiva histórica de los textos como transformadores del pasado, las convenciones existentes o los textos previos. Su finalidad es interpretativa.

c. Práctica social. Se consideran las estructuras sociales y culturales que enmarcan los eventos comunicativos en diferentes niveles: contexto de situación, ideologías, etc. Su finalidad es explicativa.

Incluso, la semiótica misma aporta un modelo comparable con las apuestas que se esbozan en los estudios del discurso. Todo esto tiene operatividad si se piensa en la doble naturaleza del lenguaje en sus orbes denotativo y connotativo; donde el primero da cuenta del lenguaje centrado y jerarquizado (lo literal), mientras el segundo es el lenguaje motivado por lo deconstructivo y diseminador o entrópico, puesto que permite que se fuguen cadenas significantes y, por tanto, sentidos múltiples gracias a los mecanismos metafórico/metonímicos. Visto esto así, se genera un esquema operativo (Klinkenberg, 2006) como el que se detalla en la tabla 1.

Tabla 1. Modelo semiótico del análisis de productos simbólicos

\begin{tabular}{|l|l|}
\hline \multicolumn{1}{|c|}{ Momento } & \multicolumn{1}{c|}{ Cualidad } \\
\hline Constitución & $\begin{array}{l}\text { Enumeración sistemática de los signos integrantes por grados complejidad. En el eje } \\
\text { sintagmático de un código predomina ora la cronosintaxis, ora la toposintaxis. }\end{array}$ \\
\hline Combinación & $\begin{array}{l}\text { Es la relación entre los signos constitutivos y la determinación explícita de sus significaciones } \\
\text { denotativas y connotativas. Aquí se privilegian interpretaciones sobre iconos y símbolos. }\end{array}$ \\
\hline Uso social & $\begin{array}{l}\text { Es la relación de los significados y sus sentidos con el contexto sociohistórico y cultural que } \\
\text { activa el usuario del sistema sígnico. Desde ese marco, se propone una interpretación, } \\
\text { intentando cualificar su funcionalidad e intencionalidad social. Su explicitación auxilia } \\
\text { la construcción de hipótesis de sentido con alcance inferencial/crítico. }\end{array}$ \\
\hline
\end{tabular}

Fuente: elaboración propia. 
De esta suerte, si comparamos los modelos de Van Dijk, Renkema y Fairclough, por parte de los representantes del $\mathrm{AD}$, la postura metódica pro- puesta por Klinkenberg, desde la semiótica teórica, encontramos las similitudes descritas en la tabla 2.

Tabla 2. Comparación de modelos de acción en AD y en semiótica

\begin{tabular}{|c|c|c|c|}
\hline Van Dijk & Renkema & Fairclough & Klinkenberg \\
\hline Textual & Lo oracional & Textual-descriptivo & Constitución \\
\hline Representacional & Lo proposicional & Discursivo-hermenéutico & Combinación \\
\hline Interpersonal & Lo pragmático & Social-explicativo & Uso social \\
\hline
\end{tabular}

Fuente: elaboración propia.

Esto nos autoriza a asociar y generalizar, ajustando, de paso, los universos que nos permitan analizar eventos festivos (tabla 3 ).

Tabla 3. Progresión metódica que une elementos de la semiótica y el análisis de lo festivo

\begin{tabular}{|c|c|c|}
\hline Klinkenberg & Semiótica & Lo festivo \\
\hline \multirow{3}{*}{$\begin{array}{l}\text { Constitución } \\
\text { cronosintáctica }\end{array}$} & \multirow{3}{*}{$\begin{array}{c}\text { Sintacnálisis o } \\
\text { constituyentes } \\
\text { organizados en } \\
\text { bloques topo- y } \\
\text { cronológicos }\end{array}$} & Preliminares o vísperas \\
\hline & & Centrales o escenificación de los referentes principales de la celebración \\
\hline & & $\begin{array}{l}\text { Las actividades complementarias que se dan } \\
\text { durante o después de las centrales }\end{array}$ \\
\hline Combinación & $\begin{array}{l}\text { Semantanálisis } \\
\text { o elementos que } \\
\text { dan sentido local } \\
\text { a cada elemento }\end{array}$ & $\begin{array}{c}\text { Campo analógico del conocimiento: simbología, axiología de } \\
\text { personajes, valores éticos y estéticos, referentes en escena } \\
\text { y referentes extradiegéticos, juegos retóricos, etc. }\end{array}$ \\
\hline Uso social & $\begin{array}{l}\text { Pragmanálisis } \\
\text { con apoyo de } \\
\text { operaciones } \\
\text { discursivas }\end{array}$ & $\begin{array}{l}\text { Lo dicho y lo callado a través de burlas, sátiras, parodias, desaprobaciones, } \\
\text { goces, asombros, calcos de otros festivales o subdiscursividad o } \\
\text { interdiscursividad en contexto, imaginarios de orientación religiosa, etc. }\end{array}$ \\
\hline
\end{tabular}

Fuente: elaboración propia.

Así, pues, a partir de esta propuesta metodológica, esbozaremos el análisis, tanto estructural como relacional de este festival realizado en San Antero, lo cual no necesariamente procede en el orden que va de lo sintáctico a lo pragmático, sino que se avanza muchas veces de manera simultánea en los tres planos o niveles, dado que lo discursivo se presenta como unidad integradora, y también porque en los discursos es muy frecuente que los vasos comunicantes de sus niveles o planos tengan límites muy difusos; de manera que su trasgresión lineal y progresiva, lejos de ser una apostasía a la forma de proceder analíticamente, es su cualidad práctica más habitual; de la misma manera que las 
formas de anchar las posibles interpretaciones surgidas de los nexos analíticos que se van estableciendo, se armonicen con un diálogo abierto y misceláneo entre, por un lado, los análisis y, por otro, los marcos de saber del analista, pues, como aseveran los profesores Cárdenas y Bejarano (2015):

La interpretación, en consecuencia, es semiosis infinita, que reenvía el sentido de signos a códigos, activa marcos de conocimiento y encuentra múltiples efectos connotativos, que pueden ser releídos bajo ciertas concepciones teóricas o de saberes y conocimientos de orden cultural. Por consiguiente, no obedece a la verdad; al contrario, acude a soportes de orden experiencial, psicológico, histórico, cultural, etc., y se fija en puntos de vista, modalidades, propósitos, modos de información, etc., sin obviar el carácter alusivo, simbólico, imaginario, alegórico, metafórico, y lúdico del lenguaje. (p. 276).

\section{El Festival del Burro examinado}

En relación con los preliminares, en los últimos años las actividades públicas del festival inician cada Domingo de Ramos con torneos de ajedrez, encuentros literarios, presentaciones de danza y de canto, rumba-terapias, concursos tradicionales, torneos de béisbol y vóley playa; además de ventas de artesanías y comidas típicas de la región. Todo esto da pie para los eventos centrales, avanzados el sábado santo; día en el que las actividades centrales comienzan en la madrugada con una alborada musical que sirve de preludio para que, después de almuerzo y sobre la vía principal de San Antero (la Calle de los Placeres), se haga un desfile de burros enmascarados, llamado "burralgata". Este deja ver pollinos con disfraces que representan diferentes personajes de la realidad sociopolítica nacional o mundial y, a través de este acto ritual basado en la máscara ${ }^{4}$, se levanta una crítica y un juego de denuncias que susurran por una justicia social, lo cual se da en el marco de un

4 Recuérdese que persona viene del latín personae, máscara que servía en la antigüedad para amplificar la voz. Es decir, lo social se vuelve máscara; una apariencia, una alteración. concurso donde al final, y con una ironía evidente, se coronan el burro y la burra mejor enmascarados. Posteriormente, en ese mismo camino, aparece una actividad complementaria, en la cual va avanzando la representación de Judas Iscariote quien, encarnado en un monigote y montado también en un burro, evoca primariamente el acto de traición o felonía denotada en los evangelios.

Obsérvese, entonces, que en este marco neotribal y pasajero, la socialidad fundada en una semana destinada al regocijo y el reencuentro, se aprovecha para ir contra los poderes opresivos a través de una estrategia kafkiana de fondo; esto es, animalizando la humanidad para poder ver la animalidad de lo humano; re-figuración de la realidad que se hace gracias a la función ritual y teatral de la máscara. De esta forma, la acción di-simuladora allí y así instaurada reacomoda la realidad social según unas presunciones que, en todo caso, dependen de la imaginación proyectiva del pueblo. Así, el Festival, con sus burros disfrazados y transitados entre comparsas y jolgorio público, permite hacer mofa y burla de sus rígidas estructuras hipostasiadas; dicho de otra forma, perturba y anula el mundo social jerarquizado gracias al exceso y la desmesura de imágenes de personajes autoritarios o dañinos que, finalmente, acortan las distancias sociales y renuevan las energías vitales.

De esta suerte, el Festival del Burro puede ser releído como la respuesta legendaria que ha adoptado este municipio costanero para avanzar y dar sentido al angustioso orden social que le toca vivir como periferia (Caro, 2006), aprovechando símbolos del mundo cristiano y, de paso, mostrando al resto de nación sus expresiones culturales más populares y sus elementos de identificación configurativos de identidad local; todo esto, centrado en el humor, manifestado, por ejemplo, en la forma de bautizar los burros con nombres de sujetos y vecinos. Pero, a pesar del plural número de actividades, lo que más sobresale es el ritual surgido con la imagen del Judas Iscariote, dada su carga religiosa; por esto, dedicaremos más esfuerzos para avanzar una descripción de 
este acontecimiento, seguido de una interpretación que dé cuenta de su sentido sociocultural.

Bien, durante el desfile de burros disfrazados, que comienza a las dos de la tarde del Sábado de Gloria, y acompasado de Banda Folclórica de San Antero, se exhibe el muñeco de Judas Iscariote, caracterizado por ser un muñeco grande y elegantemente vestido; y junto a él, el voceador, encargado de ir leyendo el Testamento, un texto que, al igual que los disfraces de los burros, presenta interpretaciones satíricas y mordaces sobre eventos y personajes de la realidad glocal y global vivida en el último año; esto sucede en diferentes puntos de la calle principal, hasta que llegan a la meta, el estadio de fútbol de San José de Petare. Por ejemplo, el inicio del Testamento de Judas, leído en el festival del año 2009 afirmaba:

Para mis grandes amigos y colegas que están pagando cana injustamente por haber firmado el tan cacareado Pacto de Paz de Ralito, les dejo mis camándulas bendecidas por el papa Benedicto XVI en el Cuarto Concilio Vaticano, para que recen día y noche, a ver si se les concede el milagrito de recobrar la libertad, y así puedan seguir trabajando tan desinteresadamente (como siempre lo han hecho) por la paz de Colombia. // Al director del famoso periódico "Opinión bajo Sinuana", le dejo pago un equipo de investigadores de amplio conocimiento en valores humanos, por si acaso se le ocurre organizar otro acto de condecoraciones, no vaya a otorgar pergaminos de reconocimiento al primer lagarto que se le ponga al frente. (Valenzuela, 2010, p. 44).

En la mitad de este escenario deportivo, se instala una artesanal horca constituida por tres maderos, uno horizontal y dos verticales amarrados con sogas y que están fijados en el suelo; esta estructura es la morada final del traidor. Frente a esta horca está la tarima en donde se hacen diferentes presentaciones y que cuenta con pantallas reproductoras de imagen. El ahorcamiento de Judas es acompañado con música en vivo, generalmente a cargo de un conjunto vallenato, escenario que se complementa con estratégicos puestos que venden bebidas alcohólicas, alimentos regionales y hasta alquiler de sillas. Antes de quemar al muñeco de Judas, el voceador, esta vez vestido de manera más formal, lee completamente el Testamento que supuestamente Judas le deja al pueblo sananterano. Una vez se hace esta lectura, varias personas bajan a Judas de la horca, lo empapan de combustible y lo vuelven a subir para que los espectadores presencien la ignición del símbolo, mientras desde la tarima un animador grita: "Se quema, se quema, el traidor". Es así como los presentes, unos a pie y otros en burro, observan cómo se va disminuyendo el asidero de tejidos hasta su consumación final, lo cual genera una respuesta de júbilo y agrado en los observadores.

Una vez los trozos del muñeco ya están carbonizados, se inicia el espectáculo de los fuegos pirotécnicos y el resto de la programación de la noche, que incluye la presentación de bailes folclóricos, auspiciados por la Casa de la Cultura de San Antero, donde no puede faltar el concurso de baile cuyo fondo coral es el género local de la champeta. Así, pues, la mirada del espectador es guiada de abajo hacia arriba (los restos del incinerado hacia el cielo iluminado), como forma alegórica de haber cauterizado un delito, al tiempo que haber taponado (por lo menos, un año más) la ruptura de la confianza y la fidelidad del otro.

Pero, hay otra cualidad del evento que llama la atención, y es la meta inclusiva e igualitaria para que interactúen los participantes, manifestado en interacciones informales y espontáneas. En efecto, toda la población que quiera participar en el desfile y el ahorcamiento y quema de Judas lo puede hacer. Entonces, se fusionan nativos, extraños y extranjeros en torno a un acto tanto teatral como discursivo y ritual, auspiciada con escenificaciones semilitúrgicas. De hecho, esta idea de un fuego purificador enclava su funcionalidad social en la noción de un fuego que purifica: “ ¿ Y quién podrá soportar el tiempo de su venida? [del Señor], ¿o quién podrá estar en pie cuando él se manifieste? Porque él es como fuego purificador, y como jabón de lavadores" (Malaquías 3:2); al tiempo que es un fuego que protege del pecado y de lo malo: "Y yo seré para ella [Jerusalén] -dice el Señor- una muralla de fuego en derredor, y para gloria estaré en medio de 
ella" (Zacarías 2:5); todo esto basado en las ya ideas presocráticas, como las de Heráclito de Efeso quien concebía simultáneamente el fuego como agente destructor y reparador ( $c f r$. Cirlot, 1982).

De esta suerte, ya en una nueva e imaginada sociedad, rompiendo lógicas maniqueas bajo los métodos de un tiempo y espacio festivos o míticos, los socios mezclados asisten a la exaltación de acontecimientos inmediatos, asociados con todo aquello que les afecta, los cuales se rememoran y se actualizan de un modo consciente en el orbe de la representación, de la mascarada para, de esta forma, lograr la redención social; esto es, la acción de recobrar algo que, aun siendo propio, está fuera de los alcances de los sujetos mismos, libertad lograda en parte con un acto comunicativo (hablar al otro es terapéutico, se sabe); nos referimos a la estrategia del testamento; es decir, la enunciación que atestigua que puede haber otro orden tras valorar el actual; esto es, que puede haber otro contrato social o, incluso, otra alianza entre los sujetos; acto que es clausurado con la burda purificación o quema de la materialización de aquel perfil centrado en Judas.

Ahora bien, intentando comprender el sentido funcional de este tipo de actos rituales y comunicativos, lo que sabemos es que la antipatía hacia el personaje expresada en la quema del muñeco Judas, lo que nos encontramos es que es un acto que, lejos de ser auténtico y local, más bien es heredado y adaptado; dicho de otra forma, se ha transculturalizado a lo largo de los siglos, un fenómeno claramente analizable con casos de subdiscursividad puesto que la quema a Judas sucede desde tiempos antiquísimos en muchos carnavales, celebrados justamente en Semana Santa, y donde la muerte del traidor está íntimamente ligada a la Resurrección del Salvador (Brisset, 1997, pp. 312 y ss.).

De suerte que en esa lista de festividades no solamente aparece el Festival del Burro del pueblo de San Antero, sino que se suman otros ya muy tradicionales como el Día de Judas, celebrado en el municipio madrileño de Robledo de Chavela; El Judas, celebrado en Samaniego, municipio del País Vasco; las Festividades de los Judíos, llevadas a cabo en Purísima del Rincón, en México; etc. Esto sucede, espacialmente unido al ritual del fuego que se instaura el Sábado Santo, donde en la Misa de Gloria se involucra el ritual litúrgico de la hoguera pascual y su multiplicación en los cirios de los asistentes, seguida de un ritual profano donde se quema Judas, como se puede atestiguar en el estudio comparativo de religiones adelantado por el antropólogo escocés James Frazer (2006).

Así, por caso, el Día del Judas españoles un ritual donde, en el Domingo de Resurrección, los juderos, jóvenes mayores de edad, ajustician a Judas, un muñeco de trapo y madera colgado a unos 18 metros de altura, bajo la modalidad de apedreamiento. Asimismo, en el largo tronco donde se cuelga al Judas se ponen avisos irónicos que hacen referencia a la situación sociopolítica del momento y se complementa con cántaros llenos de golosinas, las que también caerán por efecto del acto lapidado. "Tras la lapidación, el tronco se corta en trozos que se subastan y el pelele acaba en el pilón" (García de Sola, 1997). Algo muy similar ocurre en Talayuelas, provincia española de Cuenca (en Castilla-La Mancha), donde los jóvenes queman un Judas relleno de paja en la madrugada del Domingo de Resurrección; acción idéntica acaecida en la población de Menasalvas, en Toledo (cfr. Brisset, 1999). Y así, con algunas variantes en, por lo menos en 23 municipios españoles más ( $c f r$. Zafra y Boneque, 1997); asimismo en poblaciones de Chile, Venezuela y México donde o los sábados de Gloria o los domingos de Resurrección el monigote que representa al traidor termina entre llamas o destruido por las pedradas.

Nótese, de paso, que este ritual de quemar muñecos para exorcizar lo malo, año tras año, es muy familiar en otras zonas de Colombia y Ecuador; se trata de la quema del muñeco de Año Viejo, tradición en la que se carbonizan simbólicamente los fracasos, penas y enojos del año por abandonar y como apertura para dar la bienvenida a las esperanzas y resoluciones del año que entra. Igualmente, el disfraz y la máscara del Año Viejo representan a individuos que irritan, a políticos antipáticos, $o$ 
aún a desilusiones por errores cometidos o metas no alcanzadas. Así, de la misma forma que en fiestas españolas del Judas, a los muñecos se prenden notas burlescas e irónicas que explican por qué estos deben quemarse, sumado a qué cambios y mejoras se desean para el año nuevo.

Con todo esto, confirmamos suficientemente que el Festival del Burro no es una exclusividad de San Antero. De hecho, este tipo de festividades obedece a una tradición arcaica que las primeras civilizaciones agrícolas celebraban en el calendario lunar, el equinoccio del 20 de marzo. Como se sabe, es en esta fecha cuando la naturaleza resucita de la época invernal, lo cual instaba a la ejecución de frecuentes ritos que incluían la quema de muñecos, meros símbolos del mal y la muerte, los que desaparecían con el fuego purificador, para renacer a una nueva vida, la época primaveral. Así, se comprende el hecho de que quemar el símbolo del mal se hiciera desde mucho tiempo atrás en la época que coincide con la celebración de la Resurrección de Cristo, lo que permite asumir el renacimiento a una nueva vida. Entonces, el ritual de Judas quemado, o sea el ritual del fuego, ha servido para presentar y vivir de una forma sencilla el significado litúrgico de la Pascua, donde el paso del pecado cede la muerte a la gracia y a una nueva vida, acción que se realiza cíclicamente, pues los sujetos debemos recordar héroes divinos (mitos) para mantener el equilibrio armónico que nos permita vivir, año tras año.

A esta altura del análisis discursivo del evento, se puede afirmar, entonces, cómo la fiesta del fuego dentro de contextos religiosos se enraizó en los colectivos desde tiempos patrimoniales y se sigue celebrando aún en muchos pueblos hispanoamericanos para que el mal quede reducido a cenizas y el pueblo, así purificado, celebre la reconciliación. Por eso, al final del acto, donde se revive el mito del traidor para exorcizar lo que él conlleva, todo acababa en festejo debido a la simbólica renovación ritual que esa colectividad afirma al exorcizar ritualmente el mal que aqueja a la comunidad. Así, la inmolación de un hombre se convierte en la vía regia para devolver a los cuerpos urbano y humano su puridad y su limpieza, y para alejar ese temor ominoso donde "proyectamos en esos otros nuestra propia capacidad de corromper y de ser corruptos, para luego negarla en nosotros mismos" (GuardiolaRivera, 2017).

De suerte que el Festival del burro se convierte en una opción y operación colectiva que, desde lógicas mágico-sociales y con el aprovechamiento de las raíces cristianas de la cultura, intenta dar sentido a las vivencias trágicas y absurdas de la convivencia con la fórmula de la purificación del mal y la consecuente renovación de un periodo temporal cíclico que permita la persecución de todo lo que hace daño; algo, por cierto, ya transliterado en otras zonas de Colombia, especialmente costeras y pauperizadas, esta vez acudiendo a la imagen de la Virgen del Apocalipsis, quien aplasta y, por tanto, abate, la representación del mal que nos viene del mito del libro de Génesis: la serpiente (Sanabria, 2004).

He aquí el ingrediente que nos interesa resaltar para considerarlo como un elemento que puede dar claves para pensar y ejecutar las dinámicas de convivencia y renovación social en estas épocas de esperanza para Colombia tras el acuerdo efectuado en noviembre de 2016 que busca fundamentalmente finalizar cincuenta años de guerra civil: este tipo de festividades son hechos altamente democráticos; pues, al lado de los religiosos, permiten que todos sean iguales, que todos sean hermanos, y que allí se ponga entre paréntesis la jerarquía social que genera daño e las injusticias sociales. En los dos casos, el festivo y el religioso, o sus mezclas sutiles ya que parecen ser dos caras de la misma moneda, los dolientes se identifican a través de un símbolo que limpia y libera, que quita la pesada cruz y perdona; $y$, de paso, con el uso de estrategias discursivas como la parodia y la ironía, se desafía y compensa el absurdo social y la corrupción que se padece, a la mejor manera de una estrategia macondiana. Por eso, no resulta gratuito que en Colombia funcionen más de 850 religiones con personería jurídica y, como afirmábamos arriba, existan más de 3700 fiestas, carnavales y verbenas al año. 
En este sentido, resulta altamente confirmativo lo sucedido en la celebración del Festival del Burro en 2017. En febrero de ese año su alcalde, Dennis Chica Fuentes, destinó 65 millones de pesos (más o menos 22.400 dólares) del presupuesto del municipio para recuperar entre los habitantes de San Antero el tradicional juego del trompo y del yoyó:

El convenio fue suscrito el 3 de septiembre de 2016 con la Fundación Integral Nueva Vida (FUNAVID) y tenía una vigencia de dos meses. En el objeto se señalaba que la meta era "aunar esfuerzos para ejecutar el proyecto recreando-ando por San Antero, en aras de rescatar los juegos tradicionales en los niños, niñas y adolescentes del municipio".

Lo curioso, de acuerdo con residentes en el municipio consultados por Semana.com, es que 'si ya se hizo, nadie vio ni un trompo ni un yoyó. Nadie entiende tampoco en qué se gastan 65 millones cuando la tarea es enseñar el difícil arte de arrojar el trompo, recogerlo con la cuerda, pasarlo por el filo de un cordel, ponerlo a bailar en la uña o hacer los malabares para mantenerlo girando mientras se hacen con él maniobras difíciles de ejecutar si no se es diestro. (Revista Semana, 17 de febrero de 2017).

Este extravagante gasto, sumado al hecho de que no es la primera vez que el alcalde, también instructor de béisbol, había invertido altos montos de dinero en tareas tan vanas, costosas y, finalmente, quiméricas, pues nadie recuerda haber recibido yoyós y trompos, ni muchos menos clases para ejecutar los ancestrales juegos artesanales, suscitó la crítica del pueblo, quien aprovechó el concurso de burros del Festival 2017 para inscribir el yoyó burro y el trompo burro como acto altamente simbólico que reprochaba el acuerdo entre el alcalde Chica y FUNAVID. No obstante, la Junta Directiva del Festival impidió su inscripción, argumentando que se trataría de un plantón, de una alcaldada. Dado que los eventos del festival han tenido ese destino auténtico de parodiar y criticar, la negativa de la Junta no impidió que los dueños de esos burros los pasearan por el pueblo para recordar a propios y foráneos las arbitrariedades de la administración del momento, quien gastó buena parte de sus recursos en enseñar a los niños un juego que bien pueden aprender de tutores en sus casas.

\section{A manera de cierre}

Consideramos que, más allá de su función purificadora y proyectiva, el aporte de este festival a una posible cultura de respeto, paz y tolerancia está en la instauración del discurso del pueblo frente al discurso abstracto del poder. El burro y Judas son, finalmente, elementos simbólicos de un contradiscurso frente al de la dominación (con sus escamoteos, eufemismos y discursos del odio), que podría llamarse discurso oculto y que se manifiesta en la forma de exhibir el olvido en la fiesta, en el jolgorio, en la burla al poder, en la canción popular. En suma, una infrapolítica de la que tienen que hacer un uso táctico los moradores de una micronación corrupta e injusta, y que se manifiesta como una práctica de supervivencia, aquel residuo de voz horizontal que intenta ser oída y comprendida (Bonilla, 2006). Sobrevivimos, entonces, en la guerra (aquí entendida, básicamente, como que es lo opuesto a la paz), con formas sutiles de la comunicación ludomítica, en marcos temporales destinados para la reunión, alianza e igualdad (religión; religare), que son formas de resistencia contra la humillación y la imposibilidad de la negligencia, usando herramientas como el símbolo, la parodia, la burla colectiva, la ironía y la sátira.

\section{Agradecimientos}

Gratitudes al Centro de Investigaciones y Desarrollo Científico (CIDC), de la Universidad Distrital Francisco José de Caldas, pues gracias a su apoyo y financiación fue posible la reflexión y escritura de este artículo de reflexión, producto colateral de la investigación institucionalizada con el código 2454352415. 


\section{Referencias}

Anderson, B. (1993). Comunidades imaginadas. Reflexiones sobre el origen y la difusión del nacionalismo. México D.F.: Fondo de Cultura Económica.

Ariño, A. (1996). La ciudad ritual. Barcelona: Anthropos.

Bajtín, M. (1989). La cultura popular en la Edad Media y en el Renacimiento. Madrid: Alianza Editorial.

Bonilla, J.I. (2006). Una mirada al discurso público en contextos de terror. En A. Garcés (comp.), Pensar la comunicación (pp. 105-126). Medellín: Universidad de Medellín.

Brisset, D. (1997). Imagen y símbolo en el personaje ritual de Judas. En J. González y M. Buxó (eds.), El fuego. Mitos, ritos y realidades (pp. 301-337). Barcelona: Anthropos.

Brown, G. y Yule, G. (1983). Análisis del discurso. Visor: Madrid.

Cárdenas, J.A. y Bejarano, R. (2015). Procesos pedagógicos del lenguaje. Hacia una pedagogía integral del lenguaje. Bogotá: Uniediciones.

Caro B., J. (2006). El carnaval. Madrid: Alianza Editorial.

Cirlot, J. (1982). Diccionario de símbolos. Barcelona: Labor.

Cortés, L. y Camacho, M. (2003). ¿Qué es el análisis del discurso? Barcelona: Octaedro.

Delgado, M. (1999). El animal público. Barcelona: Anagrama.

De Friedemann, N. (1985). Carnaval en Barranquilla. Bogotá: Editorial La Rosa

De Friedemann, N. (1995). Fiestas. Celebraciones y ritos de Colombia. Bogotá: Villegas Editores.

Echeverría, G. (2008). Ontología del lenguaje. Buenos Aires: Granica.

El Tiempo (10 de febrero de 2005). Colombia: el país con más fiestas. Recuperado de http://www.eltiempo. com/archivo/documento/MAM-1636591

Escalona V., A. (2002). La cultura popular tradicional, como elemento esencial para la transformación sociocultural. Contribuciones a las Ciencias Sociales. Recuperado de www.eumed.net/rev/cccss/17/

Fairclough, N. (1998). Propuestas para un nuevo programa de investigación del análisis crítico del discurso. En L. Martín Rojo y R. Whittaker (eds.), Poder-decir o el poder de los discursos (pp. 35-54). Madrid: Arrecife.

Frazer, J.G. (2006). La rama dorada: Un estudio sobre magia y religión. Madrid: Fondo de Cultura Económica.
García de Sola, A. (1997). Pasiones vivientes para empezar, jamones para terminar. El País. Recuperado de http://elpais.com/diario/1997/03/26/ madrid/859379067_850215.html

González P., M. (1998). Fiesta y nación en Colombia. Bogotá: Magisterio.

González P., M. (2016). La fiesta en Colombia. Crea el tiempo de lo extraordinario. Credencial, 322. Recuperado de http://www.banrepcultural.org/ biblioteca-virtual/credencial-historia/numero-322/ la-fiesta-en-colombia-crea-el-tiempo-de-lo-extraordinario

Guardiola- Rivera, O. (21 de marzo de 2017). La salvación por el fuego. El Espectador. Recuperado de http://www.elespectador.com/opinion/ la-salvacion-por-el-fuego-columna-685625

Hymes, D.H. (1996). Acerca de la competencia lingüística. Revista Forma y Función, 9, 23-34. Bogotá: Universidad Nacional de Colombia.

Klinkenberg, J.M. (2006). Manual de semiótica general. Bogotá: Fundación Universidad Bogotá JTL.

Lara, S. (2014). Usos y debates del concepto de fiesta popular en Colombia. Antípoda, 21, 147-164.

Lizcano, M. y González, D. (eds.) (2009). Introducción. En Leyendo el Carnaval. Miradas desde Barranquilla, Bahía y Barcelona. Barranquilla: Ediciones Uninorte.

Martín-Barbero, J. (1987). De los medios a las mediaciones. Comunicación, cultura y hegemonía. Barcelona: Gustavo Gilli.

Martín-Barbero, J. (1992). Dinámicas urbanas de la cultura. Revista Gaceta, 12, 48-50.

Miranda, J. (2009). Las raíces africanas del carnaval de Barranquilla. En M. Lizcano y D. González (eds.). Leyendo el Carnaval. Miradas desde Barranquilla, Bahía y Barcelona (pp. 13-35). Barranquilla: Ediciones Uninorte.

Ocampo L., J. (1985). Las fiestas y el folclor en Colombia. Bogotá: Áncora Editores.

Paz, O. (2004). El laberinto de la soledad. Madrid: Cátedra.

Pereira, J. (2009). La fiesta popular tradicional del Ecuador. Quito: Fondo Editorial Ministerio de Cultura.

Renkema, J. (1999). Introducción a los estudios sobre el discurso. Barcelona: Gedisa.

Revista Semana (30 de enero de 2015). Los 3794 reinados que hay en Colombia. Recuperado de http://www.semana.com/Imprimir/416273 
Revista Semana (17 de febrero de 2017). El pueblo que se gastó 65 millones en jugar yoyó. Recuperado de http:// www.semana.com/nacion/articulo/san-antero65-millones-para-recuperar-la-tradicion-del-yo-yo

Roiz, M. (1982). Fiesta, comunicación y significado. En H. Velasco (ed.), Tiempo de Fiesta. Ensayos antropológicos sobre las fiestas en España (pp. 97-108). Madrid: Colección Alatar.

Sanabria, F. (2004). La virgen sigue apareciendo. Bogotá: Unibiblos, Universidad Nacional de Colombia.

Silva, A. (16 de noviembre de 2008). Carne de reinas. El Tiempo. Recuperado de http://www.eltiempo.com/ archivo/documento/MAM-3191047

Silva, A. (2009). La escuela desde un nuevo camino ciudadano. Revista Actualidades Pedagógicas, 53, 13-21

Turner, V. (1988). El proceso ritual. Estructura y antiestructura. Madrid: Taurus.

Triana, G. (2000). De la tradición oral a la producción audiovisual masiva. Una experiencia con las culturas populares. En D. Parias (ed.), Memorias del encuentro para la promoción y la difusión del patrimonio folclórico de los países andinos (pp. 261-267). Bogotá: Ministerio de Cultura.
Triana, G. (2006). Historia de las ciudades desde la perspectiva de los carnavales. En E. Gutiérrez y E. Cunin (eds.), Fiestas y carnavales en Colombia (pp. 11-17). Medellín: La Carreta.

Valenzuela, D.C. (2010). Análisis comunicativo del festival del burro en San Antero, Córdoba. [Tesis de pregrado]. Universidad de la Salle, Facultad de Ciencias de la Educación.

Van Dijk, T.A. (2000). Estudios del discurso: introducción multidisciplinaria III. El discurso como interacción social. Barcelona: Gedisa.

Van Dijk, T.A. (2008). Ideología y discurso. Barcelona: Ariel.

Zafra, A. y Boneque, G. (31 de marzo de 1997). La quema de Judas remata la semana de procesiones. El País. Recuperado de http://elpais.com/diario/1997/03/31/ madrid/859807463_850215.html 